\title{
sciendo
}

\section{THE EFFECT OF PRODUCTION SYSTEM AND FINISH WEIGHT ON CARCASS AND MEAT QUALITY OF KIVIRCIK LAMBS*}

\author{
Bulent Ekiz ${ }^{1 \bullet}$, Alper Yilmaz ${ }^{1}$, Hulya Yalcintan'1, Akin Yakan², Omur Kocak ${ }^{1}$, Mustafa Ozcan ${ }^{1}$ \\ 'Department of Animal Breeding and Husbandry, Istanbul University-Cerrahpasa Veterinary Faculty, \\ Avcilar, Istanbul, Turkey \\ ${ }^{2}$ Department of Animal Breeding and Husbandry, Erciyes University Veterinary Faculty, Kayseri, \\ Turkey \\ •Corresponding author: bekiz@istanbul.edu.tr
}

\begin{abstract}
Fifty-two male Kivircik lambs were used to investigate the influences of finish weight (LOW: 25-26 kg, MEDIUM: 30-31 kg and HIGH: 35-36 kg) and production system (CON: concentrate-based system, PAS: pasture-based system) on carcass and meat quality characteristics. CON lambs $(n=27)$ were weaned at $76 \mathrm{~d}$ of age and then finished on concentrate feed and alfalfa hay until slaughter. PAS lambs $(n=25)$ grazed on native pasture in the day-time and sucked their dams until slaughter. CON group grew $30 \%$ faster during the experimental period; therefore significantly fewer days were required to reach the target weight. CON lambs had higher cold carcass weight, cold dressing percentage, and produced fattier carcasses compared with those of PAS system. PAS lambs had lower meat lightness values than $\mathrm{CON}$ ones. $\mathrm{CON}$ system produced more tender meat than PAS system in terms of shear force and sensory evaluation results. Intramuscular fat of the PAS lambs had higher percentage of $\sum$ PUFA and $\sum n-3$ PUFA, and lower $n-6 / n-3$ ratio than that of $\mathrm{CON}$ ones. Finish weight had no influence on dressing percentage and carcass fatness. Meat of HIGH lambs had lower $L^{*}$ value than other groups. Panellists gave lower scores to meat of MEDIUM lambs for tenderness when compared with other groups. In conclusion, CON system might be considered to obtain higher carcass dressing, lighter meat colour and more tender meat, while PAS system had an advantage of lower $n-6 / n-3$ ratio and of higher $\sum n-3$ PUFA percentage. PAS lambs had lower fatness level than $\mathrm{CON}$ ones. Therefore, if priority is given to fatty acid composition and carcass with lower fat, PAS system might be considered. Finish weight of 35-36 kg might be preferred to increase lamb production, without any adverse effect on carcass and meat quality in both of the production systems.
\end{abstract}

Key words: fatty acids, instrumental meat quality, sensory evaluation, sheep

The need for food of animal source has increased in parallel with the fast population growth in developing countries in the Middle East. Pork consumption is very limited in these countries where Muslim population densely inhabited. Thus, red

*Funding: Research Fund of Istanbul University (UDP-35902 and 52075). 
meat requirement is mostly supplied from cattle and sheep species. Most of the sheep farms in Turkey are small-scale family enterprises, which are conducted by low-income villagers in rural areas and provide an important part of income, as in the other Middle East and some of the Mediterranean countries (Ekiz et al., 2009). Willingly consumed lamb and sheep meats in these countries, make a significant contribution in terms of meeting the animal source food requirements of low-income people (Ekiz et al., 2013).

Feed is a major expenditure for livestock enterprises. If there is sufficient pasture area and pasture conditions are favourable, grazing in the pasture is generally the cheapest way for sheep nutrition. On the other hand, pasture areas have gradually narrowed, and excessive and uncontrolled grazing resulted in the deteriorated quality of available pastures in recent years in Turkey. Therefore, natural pastures can no longer meet the nutrient requirements of lambs for finishing. These led to search for alternative systems for lamb finishing, and most of the sheep farmers preferred the intensive lamb finishing, in which lambs are weaned at 75-90 days of age and fed with concentrates until slaughter (Ekiz et al., 2012 a).

Kivircik is a medium sized and thin-tailed indigenous breed of Turkey. Meat quality of Kivircik is considered to be the best and preferred by the public among the indigenous sheep breeds in the country (Yilmaz et al., 2004). Average daily gain of Kivircik lambs after weaning at 75 day was reported as $193 \mathrm{~g}$ during 56-day finishing (Ekiz and Altinel, 2005) and $211 \mathrm{~g}$ during 70-day finishing (Karabacak and Boztepe, 2007).

Growth rate, carcass and meat quality characteristics of lambs might be affected by finishing/production system (Sañudo et al., 1998 a; Carrasco et al., 2009 a; Ekiz et al., 2013; Boughalmi and Araba, 2016). Final or slaughter weight may also influence these characteristics (Cañeque et al., 2001; Díaz et al., 2003; Martínez-Cerezo et al., 2005; Abdullah and Qudsieh, 2008; Atti and Mahouachi, 2009). Therefore, the decisions of finish weight and production system have great importance to obtain high quality lamb carcass and meat. The objective of the current study was to investigate the effects of lamb production system (concentrate-based vs. pasture-based) and finish weight (LOW: 25-26 kg, MEDIUM: 30-31 kg and HIGH: 35-36 kg) on carcass and meat quality of Kivircik lambs.

\section{Material and methods}

Animal rearing and handling procedures of the study were approved by the local Ethics Committee of Veterinary Faculty (No: 2005/ 05-109).

\section{Animal material and finishing procedures}

This research was conducted at sheep breeding unit of the Istanbul University Faculty of Veterinary Medicine, Istanbul-Turkey. Immediately after birth, lambs were allowed to suckle their dam, and they were fed only with dam's milk during the first week after birth. Afterwards, the lambs received alfalfa hay in sheepfold in 
addition to dam's milk until 76 day of age. When the mean age of lambs in the herd reached $76.5 \pm 0.6$ days, 54 male lambs, born as singles in early February, were chosen for the study. The mean weaning weights of lambs were $17.78 \pm 0.23 \mathrm{~kg}$. Lambs were allotted to two production system groups of 27 in each. Lambs in each production system were divided into 3 groups (LOW=25-26 kg, MEDIUM=30-31 kg, $\mathrm{HIGH}=35-36 \mathrm{~kg}$ ) according to the target finish weight. Initial ages and weights of lambs in six sub-groups were similar ( $\mathrm{P}=0.998$ for initial age, $\mathrm{P}=0.928$ for initial weight). Lamb production systems were:

a. Concentrate-based system (CON): CON lambs were weaned at $76 \mathrm{~d}$. Lambs were then placed in three pens $(5.0 \times 3.2 \mathrm{~m}$ each $)$ built in the sheepfold for LOW, MEDIUM and HIGH groups. Lambs from LOW, MEDIUM and HIGH finish weights were raised in groups. Lambs had free access to the alfalfa hay, concentrate feed and fresh clean water during the finishing.

b. Pasture-based system (PAS): PAS lambs were grazed at natural pasture in the day-time with their mothers until slaughter age. Lambs were kept in the sheepfold during the night with their dams. Therefore, PAS lambs suckled their dams until slaughter. They received alfalfa hay that was also given to CON lambs during the night. The natural pasture was composed of 22\% Leguminosae (Medicago spp., Trifolium spp. and Vicia spp.), 52\% Gramineae (Lolium spp. and Festuca spp.) and 26\% other families (mainly Viola spp., Conium spp., Geranium spp., Plantago spp. and Rumex spp.) (on dry matter basis) (Ekiz et al., 2012 a). Chemical composition of the alfalfa hay, concentrate feed and pasture are presented in Table 1. Metabolizable energy of concentrate feed, alfalfa hay and pasture were calculated as described by Alderman (1985).

Table 1. Chemical composition of concentrate feed, alfalfa hay and pasture used in the study (as a percentage of dry matter for all items except dry matter and metabolizable energy)

\begin{tabular}{|c|c|c|c|}
\hline Chemical composition & Concentrate feed ${ }^{\mathrm{d}, \mathrm{e}}$ & Alfalfa hay & Pasture \\
\hline Dry matter $(\%)$ & 90.30 & 92.14 & 37.95 \\
\hline Crude protein $(\%)$ & 16.90 & 15.85 & 11.5 \\
\hline Ether extract (\%) & 3.14 & 2.10 & 5.46 \\
\hline Crude cellulose $(\%)$ & 14.65 & 26.50 & 24.4 \\
\hline Ash $(\%)$ & 6.92 & 8.49 & 10.43 \\
\hline $\mathrm{NDF}^{\mathrm{a}}(\%)$ & 29.41 & 46.16 & 42.67 \\
\hline $\mathrm{ADF}^{\mathrm{b}}(\%)$ & 10.30 & 33.92 & 35.97 \\
\hline Metabolizable energy ${ }^{\mathrm{c}}(\mathrm{MJ} \mathrm{ME} / \mathrm{kg} \mathrm{DM})$ & 11.81 & 8.67 & 9.21 \\
\hline
\end{tabular}

${ }^{\mathrm{a}} \mathrm{NDF}=$ neutral detergent fibre.

${ }^{\mathbf{b}} \mathrm{ADF}=$ acid detergent fibre.

${ }^{\mathrm{c} C}$ Calculated values.

${ }^{\mathrm{d} C}$ Concentrate feed contained: wheat bran 40\%, barley 15.5\%, corn 15.3\%, DDGS (dried distillers grains with solubles) $5 \%$, soybean meal $8 \%$, sunflower meal $6 \%$, safflower meal $3 \%, \mathrm{CaCO}_{3} 2.5 \%, \mathrm{NaCl} 0.5 \%$, molasses $4 \%$, vitamin/mineral premix $0.2 \%$.

ePer $\mathrm{kg}$ of concentrate feed supplied the following mineral/vitamin premix: vitamin A, $10000 \mathrm{IU}$; vitamin $\mathrm{D}_{3}, 1500 \mathrm{IU}$; $\alpha$-tocopherol acetate, $25 \mathrm{mg}$; vitamin $\mathrm{B}_{1}, 1.5 \mathrm{mg}$; vitamin $\mathrm{B}_{2}, 2.5 \mathrm{mg}$; vitamin $\mathrm{B}_{6}, 1.5 \mathrm{mg}$; vitamin $\mathrm{B}_{12} 0.015 \mathrm{mg}$; Cal.D.Pant, $7 \mathrm{mg}$; nicotin amide, $20 \mathrm{mg}$; Mn, $50 \mathrm{mg}$; Fe, $50 \mathrm{mg}$; Zn, $50 \mathrm{mg}$; Cu, $10 \mathrm{mg}$;, $0.8 \mathrm{mg}$; $\mathrm{Co}, 0.15 \mathrm{mg}$; Se, $0.15 \mathrm{mg}$. 
Two lambs in HIGH group of PAS system had laminitis due to trauma. These lambs were not used in the research because they could not graze on the pasture. Therefore, a total of 52 lambs were slaughtered. The lambs were weighed weekly. Lambs, which reached the target finish weight at weekly weighing, were taken to the experimental slaughterhouse of Istanbul University Faculty of Veterinary Medicine.

\section{Slaughter procedures and carcass characteristics}

Lambs were slaughtered after overnight lairage. Lambs had free access to water but they were not fed during the lairage period. Immediately prior to slaughter, live weights of lambs were recorded, and lambs were electrically stunned. Hot carcass was obtained after removal of feet, skin, head, lungs and trachea, heart, liver, spleen, gastro-intestinal tract and testicles. Empty body weight (EBW) was determined by means of subtracting the weight of gastro-intestinal tract content from pre-slaughter live weight. The carcasses were chilled at $4^{\circ} \mathrm{C}$ for $24 \mathrm{~h}$, and then cold carcass weights were recorded. The dressing percentage was calculated as proportion of cold carcass weight on empty body weight. Carcasses were classified for conformation and fatness as described by Fisher et al. (2000) and then the scores given to lamb carcasses were changed into a 1-15 scale. Kidney knob and channel fat (KKCF) was removed from carcasses, and percentage of KKCF was estimated using cold carcass weight. Section area of $M$. longissimus dorsi ( $L D)$ was measured between last thoracic and first lumbar vertebrae by a planimeter as described by Boggs and Merkel (1993). Back fat thickness was determined at the same region by using a digital calliper.

Pelvic limb joint was chosen for the estimation of tissue composition. Pelvic limbs were packaged with vacuum at $72 \mathrm{~h}$ post-mortem and stored at $-18^{\circ} \mathrm{C}$ until the dissection day. One day prior to dissection, pelvic limbs were taken out from the freezer and thawed at $4^{\circ} \mathrm{C}$ for $24 \mathrm{~h}$. Pelvic limbs were dissected into lean, bone, subcutaneous fat, intramuscular fat and other tissues (larger nerves and lymph nodes, tendons, major blood vessels).

\section{Instrumental meat quality analyses}

$L D$ muscle $\mathrm{pH}$ was measured between ribs 12 and 13 using a digital $\mathrm{pH}$ meter (Testo 205, Testo AG, Lenzkirch, Germany) at three different times: i) immediately after dressing $\left(\mathrm{pH}_{0}\right)$, ii) at 45 min after dressing $\left(\mathrm{pH}_{45 \min }\right)$ and iii) at $24 \mathrm{~h}$ post slaughter $\left(\mathrm{pH}_{24 \mathrm{~h}}\right)$. Only one $\mathrm{pH}$ measurement was performed at each measurement time from each carcass.

$L D$ muscle from the right side of carcasses was removed and packaged under vacuum at $24 \mathrm{~h}$ post-mortem to measure the meat quality characteristics. These samples were stored at $4^{\circ} \mathrm{C}$ for $72 \mathrm{~h}$ until analysis. The modified Grau and Hamm pressure method was used to determine the expressed juice (\%) as described by Beriain et al. (2000). $L D$ muscle samples cut from 6th-13th thoracic vertebrae were used to determine cooking loss $(\%)$. Meat samples $(116.5 \pm 2.8 \mathrm{~g})$ that were placed in polyethylene bags were cooked in a water bath $\left(75^{\circ} \mathrm{C}\right)$ for $1 \mathrm{~h}$ (Hoffman et al., 2003). After the completion of cooking loss analysis, cooked meat samples were used for Warner-Bratzler (WB) shear force analysis. Six sub-samples $(1 \times 1 \mathrm{~cm}$ cross section and 2.5-3 cm length) were prepared from each cooked sample (Ekiz et al., 2009). Shear force analyses were performed by using Instron Universal Testing Machine (Model 
3343, Instron Corp., Norwood, MA, USA) equipped with a WB shear force apparatus. Load cell and crosshead speed were $100 \mathrm{~kg}$ and $150 \mathrm{~mm} / \mathrm{min}$, respectively.

Meat colour was measured on cut surface of $L D$ muscle slices that were taken at the first lumbar vertebrae. Colour measurements were performed from the fatfree area of the $2.5 \mathrm{~cm}$ thick samples after $1 \mathrm{~h}$ and $24 \mathrm{~h}$ blooming. Meat L* (lightness), $a^{*}$ (redness) and $b^{*}$ (yellowness) values were determined by using Minolta chromometer (Minolta CR 400, Minolta Camera Co., Osaka, Japan). Nine colour measurements were performed from each sample and colour coordinate value was determined by calculating the average of these nine measurements. The standards reported by CIE (1976) were used. Light source, aperture size and observation angle were set as illuminant D65, $8 \mathrm{~mm}$ and $2^{\circ}$, respectively.

In order to assess fatty acid composition, meat samples cut from the $L D$ muscle at the 5 th thoracic vertebrae were used. Meat samples were vacuum packaged, frozen and stored at $-18^{\circ} \mathrm{C}$ until analyses. Gas chromatography - mass spectrometry (HP Agilent 6890/5972, Santa Clara, CA, USA) was used for determination of fatty acids. Meat fat was extracted according to methodology described by Bligh and Dyer (1959). Methylation procedure was applied according to the Anonymous (2000). Methyl ester extracts of fatty acid in heptane phase were stored in deep freezer $\left(-20^{\circ} \mathrm{C}\right)$ until gas chromatography analyses. HP-88 capillary column (100-m length, $0.25 \mathrm{~mm}$ i.d. $\times 0.20-\mu \mathrm{m}$ film) was used in the separations of fatty acids. Temperatures of the detector and injector were both adjusted as $250^{\circ} \mathrm{C}$. Split ratio and total injection volume were 1:50 and $1 \mu \mathrm{L}$, respectively. n-heptane was used to wash the injector, and washing was repeated three times. Initial temperature of oven was $150^{\circ} \mathrm{C}$ for $3 \mathrm{~min}$. Oven temperature was then raised to $240^{\circ} \mathrm{C}$ with a $3^{\circ} \mathrm{C} / \mathrm{min}$ ramp rate. Chromatographic peaks, which were identified with mass spectrometers, were also verified by comparison of the retention times of internal standards (FAME Mix C4-C24, Sigma Chemical Co. Ltd., Poole, UK). Total separation time was 40 minutes. Carrier gas used in the analyses was helium and its flow rate was $0.8 \mathrm{ml} / \mathrm{min}$.

\section{Meat sensory assessment}

$L D$ muscle between 2 nd-4th lumbar vertebrae was used for sensory analyses. Samples were packaged under vacuum at $24 \mathrm{~h}$ post-mortem, aged for $72 \mathrm{~h}$ at $4^{\circ} \mathrm{C}$, then frozen and stored at $-18^{\circ} \mathrm{C}$ until panel evaluation. Prior to each panel session, frozen samples were taken out of the freezer and thawed at $4^{\circ} \mathrm{C}$ for $24 \mathrm{~h}$. The samples were cooked in a $180^{\circ} \mathrm{C}$ oven until the internal temperature reached $80^{\circ} \mathrm{C}$. Internal temperatures of samples were observed with a Testo 177-T4 data logger (Testo AG, Lenzkirch, Germany) equipped with thermocouples placed in the geometric centre of the each sample. Each cooked sample was cut into 7 sub-samples (approximately $1 \times 1 \times 1 \mathrm{~cm}$ dimensions). Sensory characteristics of sub-samples were assessed by eight-point category scale described by Sañudo et al. (1998 b). The evaluations were made by seven trained panellists, who had at least two years' experience for meat sensory assessment. Panel evaluation was carried out in eight sessions. The panellists assessed lamb odour intensity, tenderness, juiciness and flavour intensity (scale 1 = non odour, extremely tough, extremely dry and no flavour; scale $8=$ very strong lamb odour, extremely tender, extremely juicy and very strong flavour) (Sañudo et al., 1998 b). Unsalted 
crackers and water were served to panellists to freshen their mouth between each sub-sample assessment. The panel room had seven individual cabins for panellists and was equipped with red fluorescent light.

\section{Statistical analyses}

Statistical analyses were performed with SPSS 13.0 (SPSS Inc, Chicago, Illinois, USA). Data for carcass and instrumental meat quality characteristics were analysed using the General Linear Model (GLM) procedures based on a $3 \times 2$ factorial arrangement of finish weight group (LOW, MEDIUM and HIGH), production system (CON and PAS systems) and their respective interactions. In the analysis of sensory panel data, a two stage process was applied. In the initial analysis, the raw data was adjusted for session and panellist to derive LS-means for each animal. Then, GLM procedures based on a $3 \times 2$ factorial arrangement was used.

\section{Results}

\section{Carcass quality}

The effects of finish weight and production system on carcass characteristics and pelvic limb composition are presented in Tables 2 and 3. An increase in weights of empty body and cold carcass and lean/bone ratio were observed with the increase in finish weight $(\mathrm{P}<0.001)$. Moreover, lambs of HIGH group had higher $L D$ muscle section area and conformation score than lambs of other weight groups $(\mathrm{P}<0.001)$. On the other hand, different finish weight groups had similar mean values with respect to ADG, dressing percentage, chilling loss, back fat thickness, KKCF percentage, proportions of lean, subcutaneous fat, intermuscular fat, total fat and lean/fat ratio.

Production system had significant influence on carcass characteristics, except final weight, $L D$ muscle section area and lean/bone ratio. CON lambs had higher mean values for ADG, empty body weight, cold carcass weight, dressing percentage, conformation score and fatness parameters (fatness score, back fat thickness, KKCF percentage, omental and mesenteric fat percentage, proportions of subcutaneous fat, intermuscular, total fat in pelvic limb) compared with lambs of PAS system. On the other hand, chilling loss, proportions of lean and bone in pelvic limb and lean/fat ratio were higher in PAS lambs than $\mathrm{CON}$ ones.

Effects of weight group $\times$ production system interaction on cold carcass weight, fatness score and omental and mesenteric fat percentage were significant $(\mathrm{P}<0.05)$. CON and PAS lambs slaughtered in LOW weight had similar cold carcass weight, whereas CON lambs of MEDIUM and HIGH groups had higher cold carcass weight than PAS ones (Table 2). Lambs of MEDIUM and HIGH weight groups reared under CON system had higher omental and mesenteric fat percentage and fatness score than those of LOW group $(\mathrm{P}<0.05)$, while such a significant difference was not observed in lambs of PAS system. On the other hand, CON lambs slaughtered in MEDIUM and HIGH weight groups had higher omental and mesenteric fat percentage and fatness score than PAS lambs, while differences between CON and PAS lambs in terms of these characteristics were not significant in LOW weight group. 


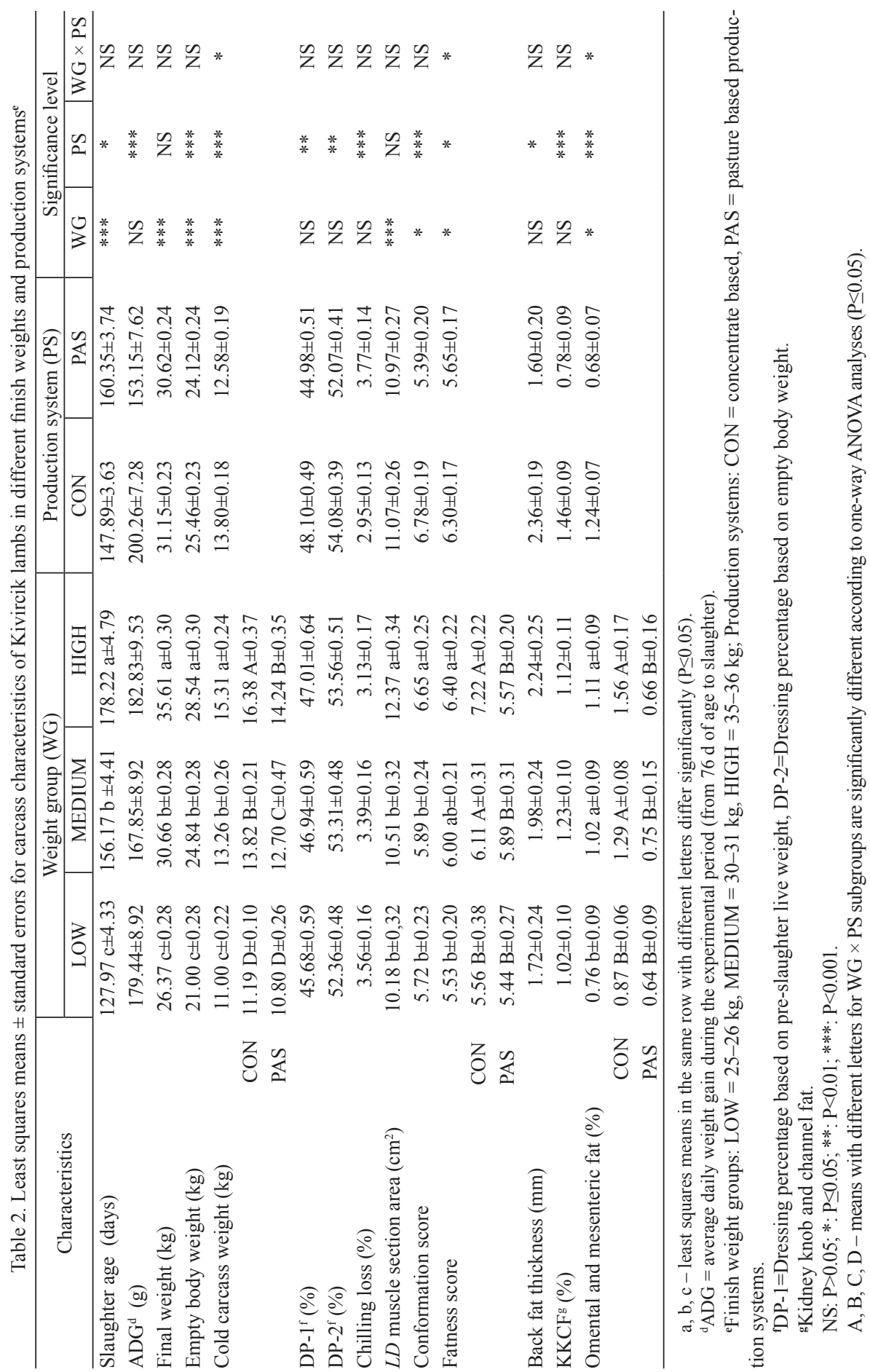




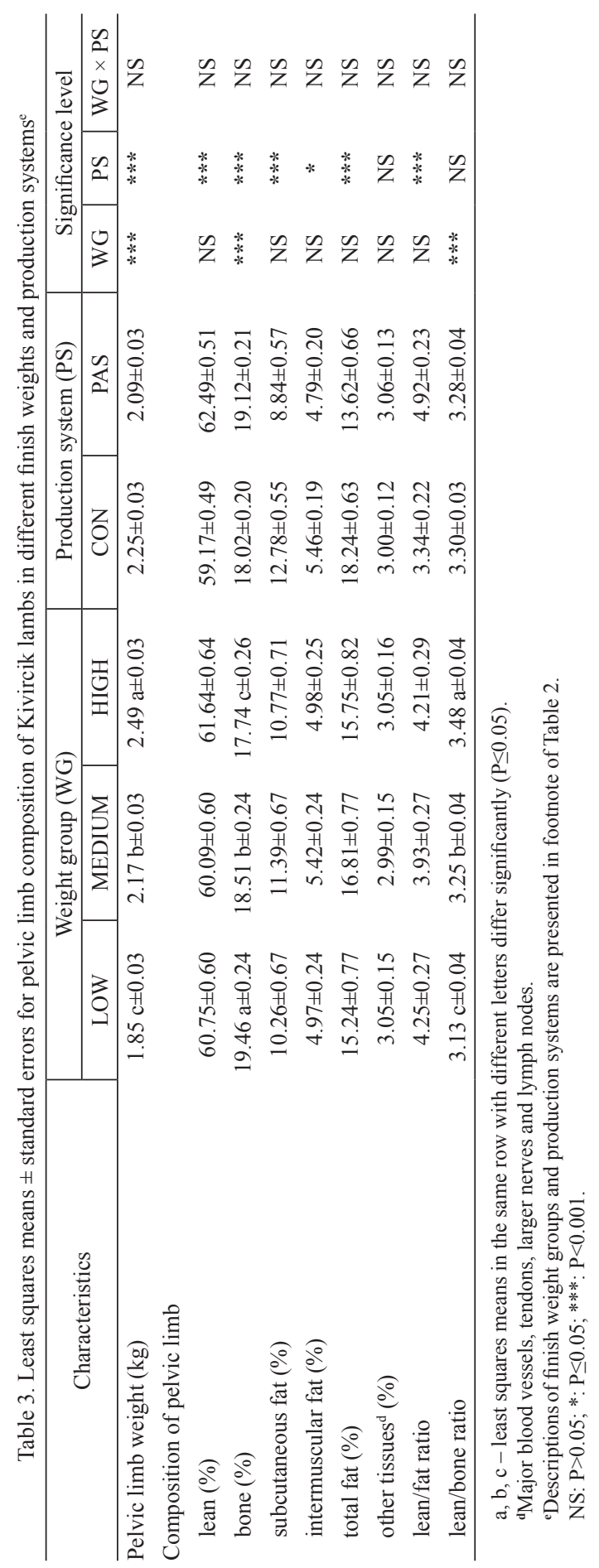




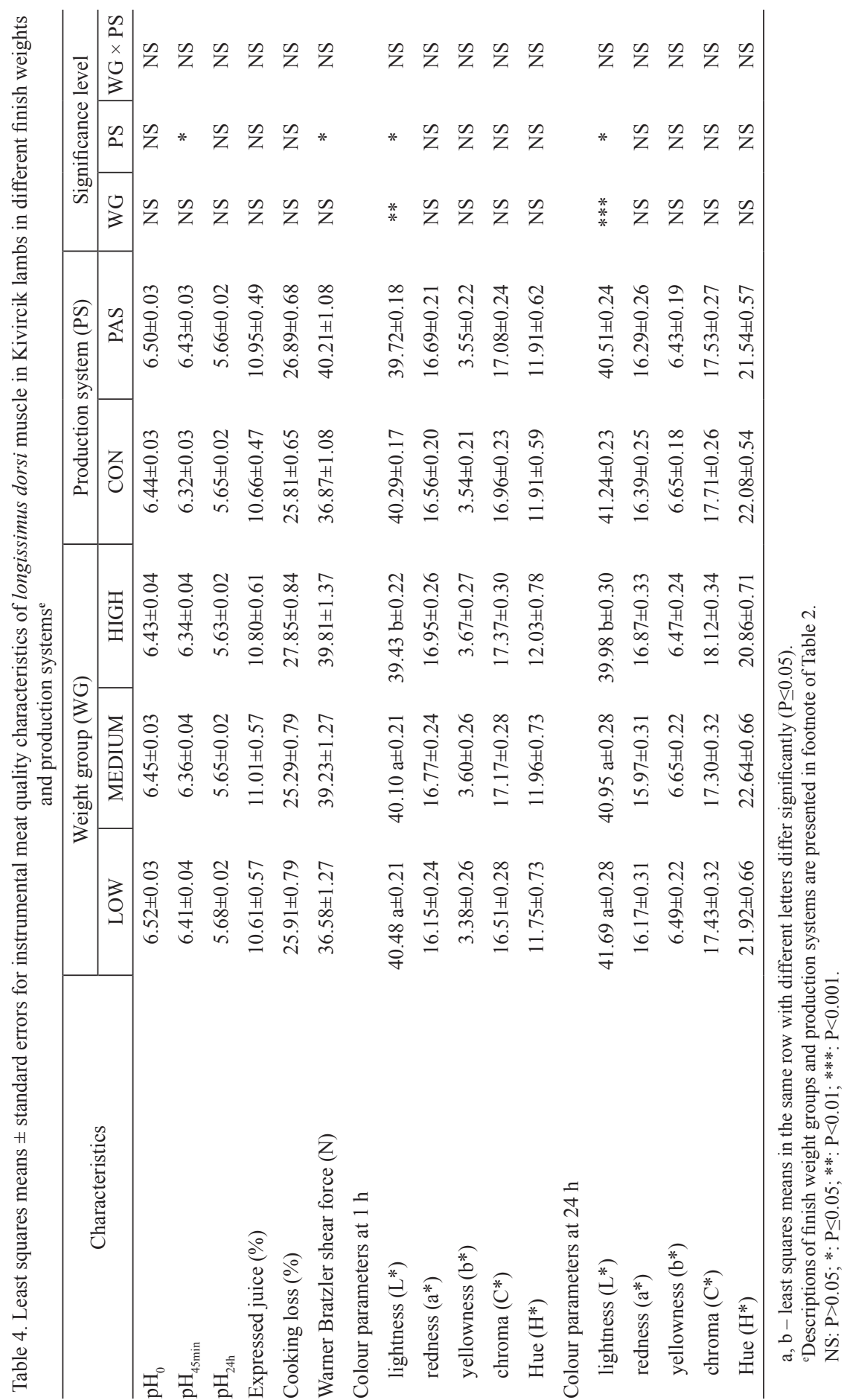




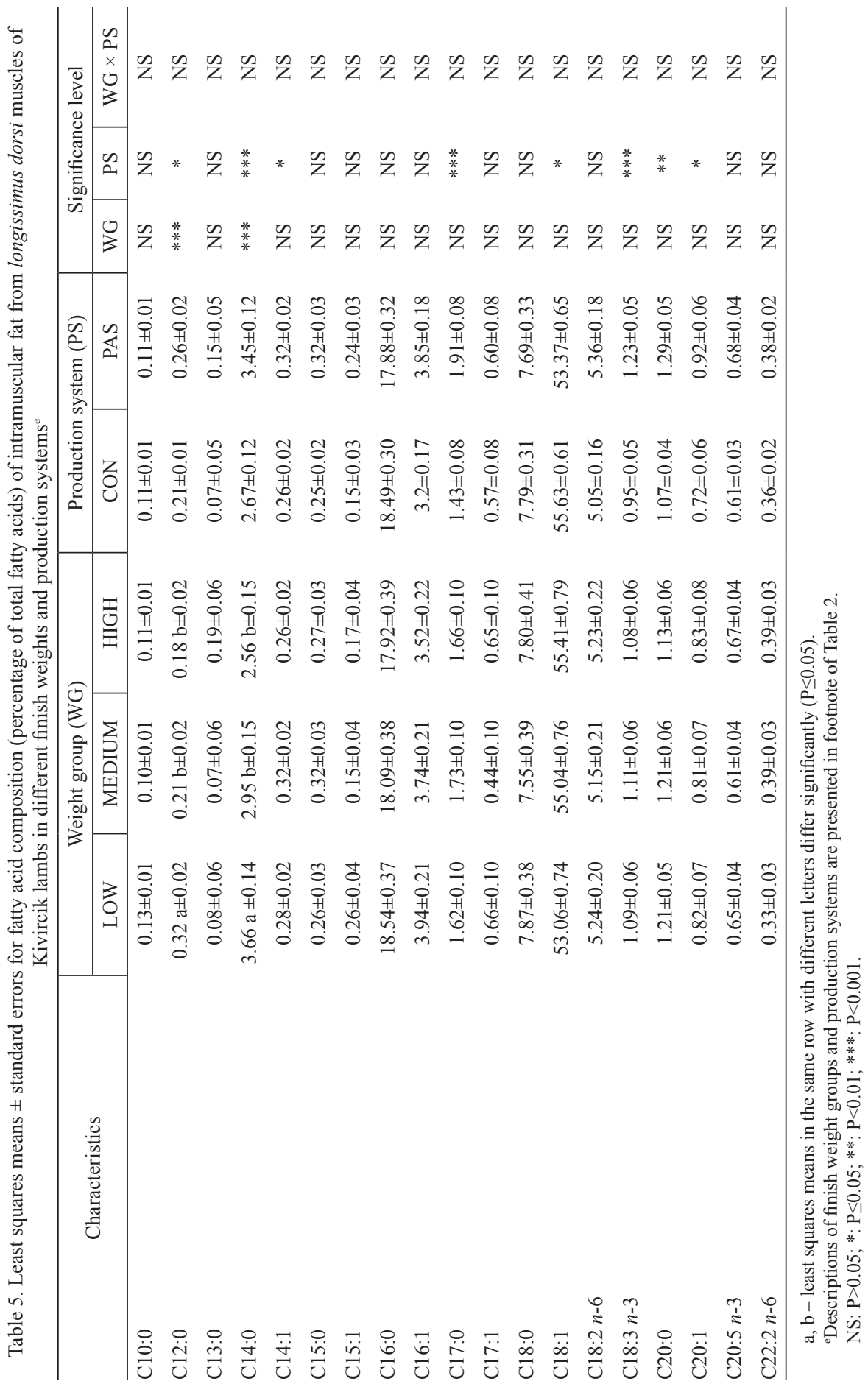




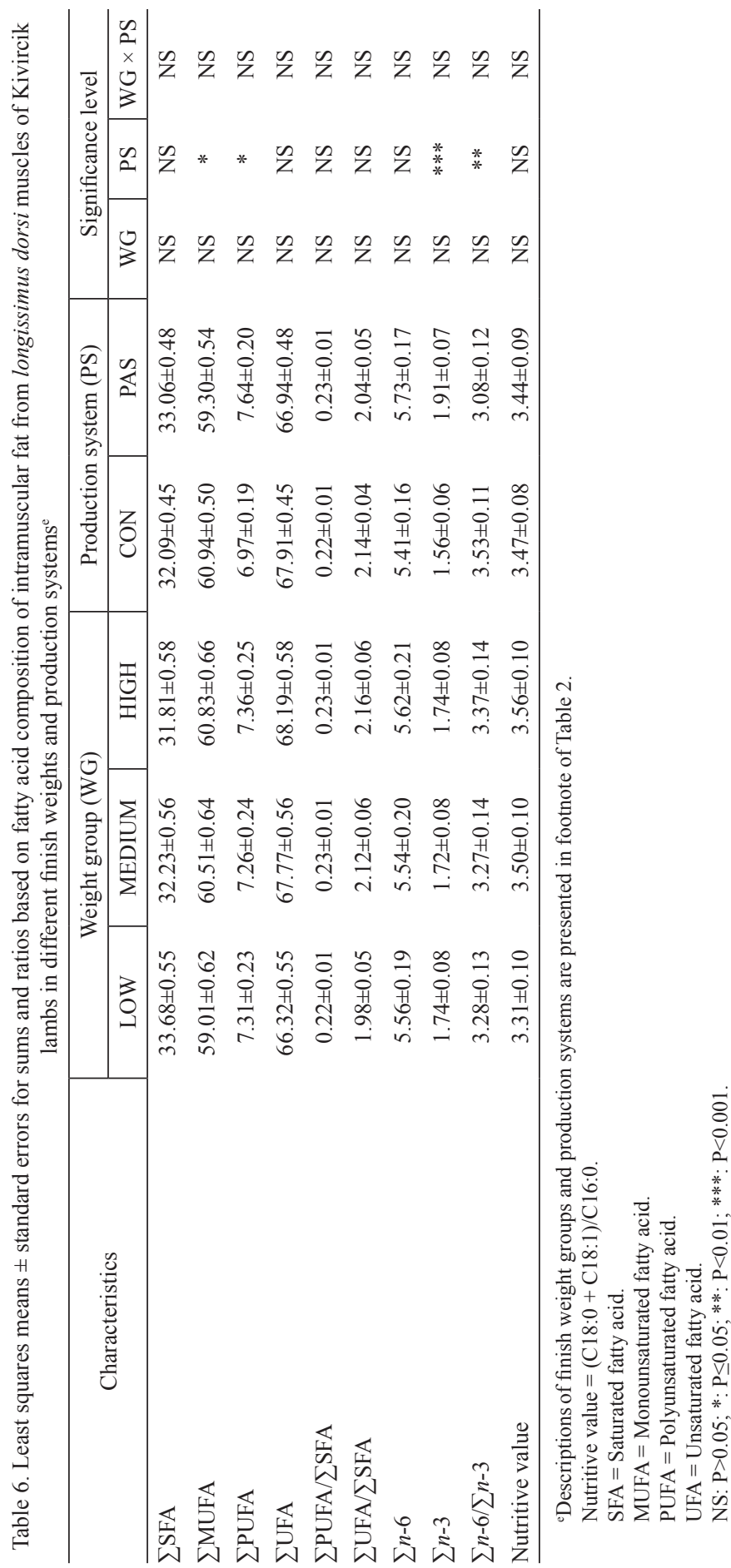




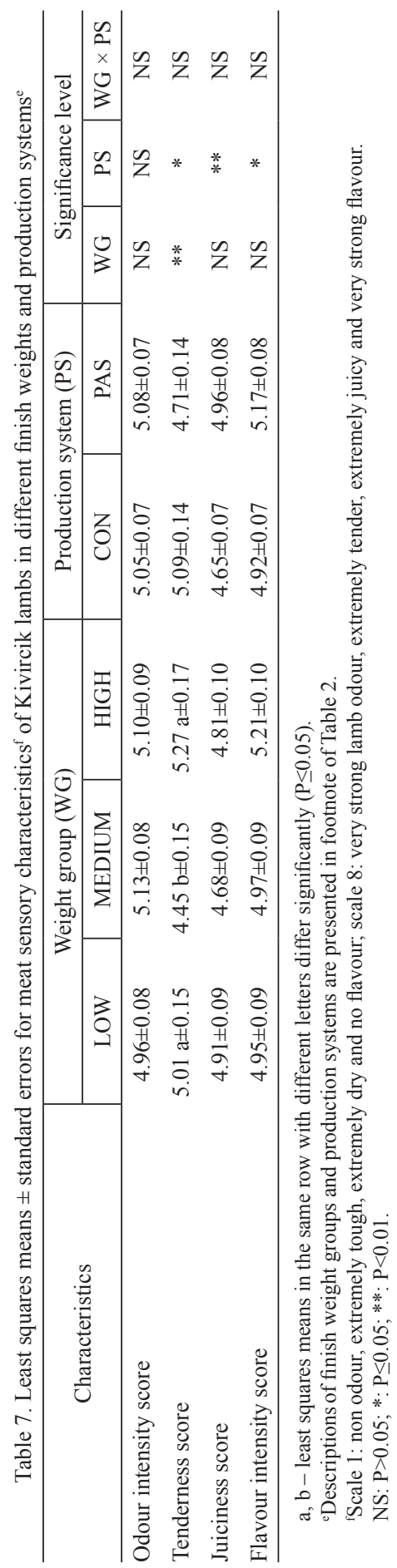




\section{Meat instrumental quality}

Finish weight had no significant influence on meat $\mathrm{pH}$, expressed juice, cooking loss, WB shear force and meat colour parameters $(\mathrm{P}>0.05)$, except lightness (Table 4). Meat of HIGH group had lower lightness values at $1 \mathrm{~h}(\mathrm{P}<0.01)$ and $24 \mathrm{~h}(\mathrm{P}<0.01)$ after cutting than those of other groups. Effects of production system on $\mathrm{pH}_{45 \min }$, WB shear force, meat lightness at $1 \mathrm{~h}$ and $24 \mathrm{~h}$ after cutting were significant $(\mathrm{P}<0.05)$. CON lambs had lower $\mathrm{pH}_{45 \min }$ and $\mathrm{WB}$ shear force values, and higher meat lightness values at $1 \mathrm{~h}$ and $24 \mathrm{~h}$ after cutting compared with those of PAS lambs.

\section{Fatty acids}

Finish weight had no significant influence on percentages of individual fatty acids, except C12:0 and C14:0 (Table 5). Meat samples from lambs of LOW group showed higher proportions of C12:0 and C14:0 compared with MEDIUM and HIGH groups. Meat of PAS lambs had higher proportions of C12:0, C14:0, C14:1, C17:0, C18:3 n-3, C20:0, C20:1, $\sum$ PUFA and $\sum n-3$ compared with CON lambs. However, proportion of C18:1, $\sum$ MUFA and $\sum n-6 / \sum n-3$ were higher in CON lambs (Table 6).

\section{Meat sensory assessment}

Results of sensory characteristics of meat in different finish weight groups and production systems are presented in Table 7. Finish weight had no significant influence on meat sensory characteristics, except tenderness score. Panellists gave lower scores to meat of MEDIUM group for meat tenderness compared with other weight groups $(\mathrm{P}<0.01)$. The effect of lamb production system on meat tenderness $(\mathrm{P}<0.05)$, juiciness $(\mathrm{P}<0.01)$ and flavour intensity $(\mathrm{P}<0.05)$ were significant. Tenderness scores of CON lambs were higher than those of PAS lambs, while higher scores for juiciness and flavour intensity were given to meat of PAS lambs.

\section{Discussion}

\section{Carcass quality}

In Turkey, pricing of lamb carcasses is based on carcass weight. However, excessively fat carcasses are not preferred by the butchers, since customers mostly demand trimming off the extra fat from meat without any payment for this fat. Therefore, decision of finish weight is an important issue in order to supply a profitable lamb production. Growth rate of Kivircik lambs (ADG of $200 \mathrm{~g}$ in CON system and $153 \mathrm{~g}$ in PAS system) might be considered low compared to lambs from meat type breeds reared in Turkey. These ADG values were in accordance with previous reports (177225 g) for Kivircik lambs (Ekiz and Altınel, 2005; Karabacak and Boztepe, 2007; Ekiz et al., 2012 b; Yalcintan et al., 2017). On the other hand, mutton-wool type breeds, such as Karacabey Merino and Anatolian Merino, are reared in some regions of Turkey. The current ADG values were lower than those reported for Karacabey Merino (289-301 g) and Anatolian Merino (306 g) lambs (Ozcan et al., 2005; Şahin and Boztepe, 2010; Sezenler et al., 2013). Low growth rates of Kivircik lambs limit 
the slaughter of these lambs at high weights. In the current study, cold carcass weight was increased with the rise in finish weight, however dressing percentage was not influenced by finish weight. Similar results were also reported previously by Santos et al. (2007) for suckling lambs of the Churra da Terra Quente breed and by Rajkumar et al. (2014) for Muzaffarnagari lambs raised under intensive production system.

Finish weight did not influence objective carcass fatness parameters (back fat thickness, KKCF percentage, proportions of subcutaneous, intermuscular and total fat), while non-carcass fatness parameter investigated in the study (omental and mesenteric fat percentage) was lower in lambs of LOW group compared with MEDIUM and HIGH weight groups. Supporting the current results, Cañeque et al. (2001) determined non-significant differences between Talaverana lambs slaughtered at 24 and $28 \mathrm{~kg}$ live weights regarding carcass fatness. However, increasing carcass fatness as lambs slaughtered at heavier weights were reported for Talaverana lambs fattened on pasture or sheepfold (Díaz et al., 2002), for Manchego-breed suckling lambs (Díaz et al., 2003) and for Muzaffarnagari lambs raised under intensive production system (Rajkumar et al., 2014). Similar fatness levels of LOW, MEDIUM and HIGH weight groups in PAS lambs can be expected due to low energy intake of these lambs. Carrasco et al. (2009 b) noted that when energy intake is limited, the fat depots are less developed. But, non-significant weight group $\times$ production system interaction effect on back fat thickness, KKCF percentage, proportions of subcutaneous, intermuscular and total fat indicate that non-significant weight group influence on these characteristics was valid in both PAS and CON systems. This result might indicate that weight differences among groups were not adequate to form significant differences in terms of fatness level. On the other hand, it is noteworthy that subjective fatness scores and omental and mesenteric fat percentage determined for lambs of LOW group were lower than those of MEDIUM and HIGH groups in CON system. However, such a weight group effect was not observed in PAS system. Carrasco et al. (2009 b) reported the mesenteric fat to be the first developed fat depot, while subcutaneous fat was the last developed depot. This may explain why the interaction effect was significant for the omental-mesenteric fat percentage, while this effect was not significant on the other fat depots.

CON lambs had higher ADG than PAS lambs. Therefore, time needed to reach target slaughter weight was significantly shorter for CON lambs. A higher growth rate in CON lambs compared with PAS ones might be the result of differences between production systems in terms of food resources. CON lambs might have received higher amounts of both protein and energy, compared with PAS lambs. Moreover, PAS lambs did not have access to vitamin and mineral supplement in the study and they may have experienced borderline supply of some vitamins or trace minerals leading to lower animal performance. Contrary to the current results, studies (Díaz et al., 2002; Priolo et al., 2002; Atti and Mahouachi, 2009) reporting similar ADG for grazing and stall lambs were also available. A lack of rotational grazing or systematic pasture management may have led to excessive usage of pastures and decreased pasture quality, and consequently lower growth rate of PAS lambs.

CON lambs had higher cold carcass weight than lambs reared under PAS system. This result was expected, since empty body weights of CON lambs were also higher 
than those of PAS lambs. On the other hand, Priolo et al. (2002) explained higher carcass weight in stall lambs fed concentrates compared with pasture-fed lambs by the lower proportion of the digestive tract in stall lambs. Supporting the current study, Borton et al. (2005) also reported lower dressing percentage in lambs fed on pasture than those of concentrate-fed lambs, and explained this result by an increase in the size of digestive tract and decrease in the external fat cover resulted from forage finishing systems.

A higher chilling loss in PAS lambs than CON counterparts might be explained by lower back fat thickness in PAS lambs. Supporting the current results, numerous authors (Díaz et al., 2002; Priolo et al., 2002; Borton et al., 2005; Ekiz et al., 2013) also reported higher carcass fatness in concentrate-fed lambs compared with that of lambs grazed on pasture. In most of the previous studies (Díaz et al., 2002; Priolo et al., 2002; Cañeque et al., 2003; Perlo et al., 2008; Ekiz et al., 2013), lower carcass fatness in lambs finished at grazing based systems compared with lambs finished at sheepfold was explained by higher physical activity or greater energy expenditure of grazing lambs. According to Cañeque et al. (2003) and Ekiz et al. (2013), one other possible explanation for lower carcass fatness in grazing lambs might be their lower energy intake. So, lower carcass fatness in PAS lambs found in the current study might be due to higher physical activity and/or lower energy intake of these lambs compared with CON lambs, which were fed with concentrate in the sheepfold.

\section{Meat instrumental quality}

Ultimate meat $\mathrm{pH}$ values $_{24}$ according to reports by Priolo et al., 2002 and Peña et al., 2009) between 5.5 and 5.8 could be defined as acceptable quality range (Hedrick et al., 1994). According to this fact, ultimate meat $\mathrm{pH}$ values measured in the current study seem to be within the acceptable range. In the earlier studies, effect of finish/slaughter weight on meat $\mathrm{pH}$ was conflicting. Although many authors (Díaz et al., 2002, 2003) observed significant increase in ultimate meat $\mathrm{pH}$ with increased slaughter weight, some other studies reporting non-significant differences in ultimate meat $\mathrm{pH}$ among lambs slaughtered at different weights were also available (Santos et al., 2007). There was no significant difference between lambs reared under CON and PAS systems for ultimate meat $\mathrm{pH}$. This result coincides with previous reports by Díaz et al. (2002) for Talaverana lambs fattened on pasture or sheepfold and by Priolo et al. (2002) for grass-fed or stall-fed Ile de France lambs. On the other hand, studies reporting lower ultimate meat $\mathrm{pH}$ for concentrate fed lambs as compared to PAS fed lambs were also available (Hopkins et al., 2001; Perlo et al., 2008). Significant differences in ultimate $\mathrm{pH}$ among production systems/feeding systems have been attributed to the variation in muscle glycogen contents (Priolo et al., 2001; Perlo et al., 2008). High energy diets may protect animals from potentially glycogen depletion stressors (Immonen et al., 2000). However, pasture fed lambs may have no disadvantage under conditions of low stress when compared to feed supplemented or feedlots lambs (Lowe et al., 2002).

Meat colour is an important characteristic used by the consumer to evaluate the freshness and quality of the meat at the point of purchase (Teke et al., 2018). In Turkey, like the Mediterranean countries of EU, pale or pink lamb meat is preferred by 
consumers (Ekiz et al., 2012 b). In the current study, meat of CON lambs had higher lightness values at $1 \mathrm{~h}$ and $24 \mathrm{~h}$ after cutting than those of PAS lambs. This result coincides with earlier studies, which report higher meat lightness in lambs raised on concentrate based systems compared with their pasture grazed counterparts (Díaz et al., 2002; Priolo et al., 2002; Cañeque et al., 2003; Ekiz et al., 2012 a). Beriain et al. (2000) reported that the muscles used when walking produce more energy, therefore they need more oxygen, and finally they might be darker. Cañeque et al. (2003) noted that greater lightness in $L D$ samples of drylot lambs compared to pasture lambs might be probably due to differences in physical activity levels. In the present study, differences in physical activity might be probably one of the reasons of differences in $\mathrm{L}^{*}$ values between $\mathrm{CON}$ and PAS lambs.

Finish weight did not affect meat instrumental quality, except meat lightness value measured at $1 \mathrm{~h}$ and $24 \mathrm{~h}$ after cutting. Lambs of HIGH group had darker meat compared with lambs of LOW and MEDIUM groups. Supporting the current results, numerous authors (Cañeque et al., 2001; Santos-Silva et al., 2002; Díaz et al., 2003) also reported decreased meat lightness $\left(\mathrm{L}^{*}\right)$ as slaughter weight increased. Díaz et al. (2003) noted that darkening of lamb meat as slaughter weight increases might be due to pigment content increase by age. According to Khliji et al. (2010), lightness and redness values of fresh lamb meat, which are equal to or exceed 34 and 9.5, respectively, are considered acceptable by consumers.

Expressed juice and cooking loss were not influenced by production system. The non-significant influences of production system or feeding system were previously observed for water holding capacity of Talaverane lambs fattened on pasture and weaned at $45 \mathrm{~d}$, at $65 \mathrm{~d}$ or unweaned until slaughter (Cañeque et al., 2001), amount of expressed juice of Talaverana lambs fattened on pasture or sheepfold (Díaz et al., 2002) and cooking loss of forage-fed or concentrate-fed Churra Tensina light lambs (Carrasco et al., 2009 a).

Meat samples of CON lambs were tenderer than meat of PAS lambs according to the results of WB shear force analysis. Carcass fatness may influence the WB shear force value (Sañudo et al., 1998 a). Sañudo et al. (2000) reported a decrease in shear force value and toughness with increasing carcass fatness class in Rasa Aragonesa lambs. In a previous study (Perlo et al., 2008), lower shear force values for lambs fed with concentrate based system compared with grass lambs were attributed to higher fatness of lambs fed concentrate based system. Therefore, possible explanation for more tender meat in CON lambs compared to PAS lambs in the current study might be higher fatness level (Tables 2 and 3) in CON lambs. Growth rate of lambs may influence the collagen content and solubility, and therefore meat tenderness (Maiorano et al., 2009). It was reported that muscle collagen and crosslink amount are reduced by a fast growth rate (Maiorano et al., 2009). Sylvestre et al. (2002) observed lower levels of total and insoluble collagen content in lambs expressing a high growth rate than the slower-growing lambs. Sañudo et al. (1998 b) found a higher tenderness in Merino lambs compared with Rasa Aragonesa breed, and the authors explained this result by high ADG in Merino lambs, which produces an increase in soluble collagen. Hence, higher ADG of CON lambs in the current study might be another explanation for lower WB shear force value in CON lambs. 


\section{Fatty acids}

The most abundant fatty acid was oleic acid (C18:1) in lambs of all weight groups (53.06-55.41\%) and also in both of the production systems (53.37$55.63 \%)$. Percentages of palmitic acid (C16:0, 17.88-18.54\%) and stearic acid (C18:00, 7.69-7.87\%) followed oleic acid. These findings were in line with reports by Atti and Mahouachi (2009), who stated that the prevalence of oleic, palmitic and stearic acids consisted of about $80 \%$ of the total fatty acids in longissimus muscle of Barbarine lambs.

When effects of finish weight on individual fatty acids were examined, significant influence was only detected on percentages of lauric and myristic acids. Percentages of these fatty acids were higher in LOW group than MEDIUM and HIGH groups. In ruminants, $\mathrm{C} 12: 0$ and $\mathrm{C} 14: 0$ fatty acids are predominantly provided from the diet and the fat of maternal milk is rich in these fatty acids (Cañeque et al., 2001; Juárez et al., 2008). Numerous researcher (Velasco et al., 2000; Cañeque et al., 2001; Ekiz et al., 2013) reported that milk yield of dam, suckling length and duration after weaning might affect the fatty acid composition of lamb meat. In the current study, PAS lambs suckled their dams until slaughter. However, due to the decrease in the share of dam milk in the diet as the age increases, it is thought that lauric and myristic acid percentages were higher in the meat of LOW group. In the CON system, the higher percentages of these fatty acids in the LOW group may be related to the shorter duration of time after weaning in the LOW group compared to the MEDIUM and HIGH groups. Supporting the current results, a decrease in percentages of lauric and myristic acids in intramuscular fat with increasing slaughter weight (Beriain et al., 2000; Díaz et al., 2002) was previously reported, and was explained by the presence of these fatty acids in ewe's milk and more consumption of maternal milk by younger lambs in their daily diet.

Production system had significant influence on percentage of lauric acid (C12:0), myristic acid (C14:0), margaric acid (C17:0) and arachidic acid (C20:0). Percentages of these fatty acids were higher in meat of PAS lambs than CON ones. Santos-Silva et al. (2002) also observed a higher myristic acid in lambs raised on pasture than concentrate fed lambs. The authors explained this result by the raising of pasture lambs together with their mothers, as in the current study, and by the higher myristic acid content of ewe's milk compared with concentrates. Production system had no significant influence on percentages of palmitic and stearic acids, which consist of vast majority of SFAs. As previously reported by Rowe et al. (1999), intramuscular fat of the CON lambs presented higher percentage of oleic acid and total MUFA than those of PAS lambs, while percentages of $\alpha$-linolenic acid (C18:3 n-3) and total PUFA were higher in meat of PAS lambs. Most of the previous studies (Dìz et al., 2002; Santos-Silva et al., 2002; Özcan et al., 2015) on lambs fed concentrate diets vs. grass/pasture agree that the higher percentage of $\alpha$-linolenic acid in intramuscular fat of grass-fed lambs might be attributed to high concentration of this fatty acid in grass lipids.

Nutritionists suggest a low intake of SFA and an increased PUFA/SFA ratio in diet, to reduce the prevalence of coronary heart diseases (Williams, 2000). In the current study, production system had no significant influence on $\sum$ SFA and $\sum$ PUFA/ $\sum$ SFA. 
On the other hand, intramuscular fat of the PAS lambs presented higher percentage of $\sum n-3$ PUFA and lower $\sum n-6 / \sum n-3$ ratio than those of CON lambs. These results are in accordance with most of the previous reports, which compared the fatty acid profile of lambs finished at pasture-based vs. concentrate-based systems (SantosSilva et al., 2002; Ricardo et al., 2015). Significant differences in $\sum n-3$ PUFA and $\sum n-6 / \sum n-3$ ratio between PAS and CON lambs might be attributed to differences in composition of the dietary lipids (Díaz et al., 2002; Ekiz et al., 2013). It is known that grass contains a high level of linolenic acid (C18:3), precursor of the $n-3$ series of fatty acids, while there is a predominance of linoleic acid (C18:2), precursor of $n-6$ series of fatty acids, in lipids of concentrates (Enser et al., 1998; Díaz et al., 2002). Differences between PAS and CON lambs regarding $\sum n-3$ PUFA and $\sum n-6 / \sum n-3$ ratio might also be due to the differences regarding biohydrogenation activity of polyenoic fatty acids and rumen transit time (Petrova et al., 1994; Díaz et al., 2002; Wood et al., 2008). Concentrate-based diets lead to a greater amount of available carbohydrates, which shortens the length of time food stays in the rumen and reduce the biohydrogenation of polyenoic fatty acids (Petrova et al., 1994; Díaz et al., 2002). A shorter rumen transit time in concentrate diets than fibrous forage diets may limit the opportunities for microbial biohydrogenation (Wood et al., 2008).

No finish weight-related differences were observed for total fatty acids and ratios in the current study. These results in accordance with reports by Díaz et al. (2003) and Peña et al. (2009), who compared the fatty acid profile of lambs slaughtered at different weight groups. However, the researches reporting significant increase in total MUFA and decrease in SFA with increasing slaughter weight (Beriain et al., 2000; Díaz et al., 2002) were also available. Differences among studies could be attributed to the ranges of slaughter weights used in these studies. No significant finish weight influence on these parameters in the current study might be explained by the fact that the interval between slaughter weights were small.

Optimal ratio of $n-6 / n-3$ PUFA ratio for the human diet is suggested as $<4$ : 1 (Vatansever and Demirel, 2009) and fats having higher values than this recommendation are considered unfavourable (Santos-Silva et al., 2002). According to this fact, $n-6 / n-3$ PUFA ratio obtained for PAS (3.08) and CON (3.53) lambs may indicate acceptable meat quality from the nutritional point of view.

\section{Meat sensory evaluation}

Differences among finish weight groups for meat sensory characteristics, except tenderness score were not significant. Meat of MEDIUM group was evaluated as tougher than other groups by panellists. Supporting the current result Lloyd et al. (1980) also did not find any significant differences between lambs slaughtered at 54 and $64 \mathrm{~kg}$ live weights in terms of flavour and juiciness, while mean scores given for tenderness were higher in heavier lambs.

Panellists gave higher scores to meat of CON lambs for sensory tenderness compared with PAS lambs. Priolo et al. (2002) for Ile de France lambs and Ekiz et al. (2012 a) for Kivircik lambs also obtained similar result, and the authors explained this finding by higher carcass fatness in lambs fed concentrates compared to lambs finished at pasture. According to Priolo et al. (2002) significant effect of carcass fat- 
ness on meat sensory tenderness might be caused by the direct effect of the fat which is softer than lean and/or to an indirect effect of reduced muscle fibre shortening.

Mean scores for flavour intensity given to meat of CON lambs were lower than those of PAS lambs. Supporting the current result, Fisher et al. (2000) found lower flavour intensity in Suffolk lambs finished on concentrates than Suffolk lambs fed grass, and explained this result by the difference in terms of muscle fatty acid composition. One of the reasons of higher flavour intensity in PAS group might be connected to the fact that these lambs suckled their mothers besides grazing at pasture as reported by Sañudo et al. (1998 b), who found higher flavour intensity scores for unweaned lambs compared with their weaned counterparts.

\section{Conclusion}

In the conditions of the current study, finish weight of 35-36 kg for Kivircik lambs might be practised without any adverse effect on carcass and meat quality in both of the production systems. Lamb finishing system based on concentrates at sheepfold might be preferred from the production quantity and meat quality points of view. PAS production system in which lambs were grazed at pasture and also suckled their mothers until slaughter might be considered if priority is given to the fatty acid composition of meat and carcass with lower fat.

\section{References}

A bdullah A.Y., Quds i eh R.I. (2008). Carcass characteristics of Awassi ram lambs slaughtered at different weights. Livest. Sci., 117: 165-175.

A lderman G. (1985). Prediction of the energy value of compound feeds. In: Recent Advances in Animal Nutrition, Haresing W., Cole D.J.A (eds). Butterworths, London, pp. 3-52.

A nonymous (2000). Aceites y grasas de origen vegetal. Preparacion de esteres metilicos de acidos grasos. Associacion Espanola parala Normalizacion y Certificacion (AENOR), UNE-EN ISO 5509.

A tti N., Mahou chi M. (2009). Effects of feeding system and nitrogen source on lamb growth, meat characteristics and fatty acid composition. Meat Sci., 81: 344-348.

B eria in M.J., Hor c a d a A., P urro A., Lizas o G., Chas co J., Mendizabal J.A. (2000). Characteristics of Lacha and Rasa Aragonesa lambs slaughtered at three live weights. J. Anim. Sci., 78: 3070-3077.

B ligh E.G., D y e r W.J. (1959). A rapid method of total lipid extractions and purification. Can. J. Biochem. Physiol., 37: 911-917.

B o g g s D.L., M erk e l R.A. (1993). Live Animal Carcass Evaluation and Selection Manual, Iowa, USA, Kendall Hunt Publishing Company.

B ort o n R.J., L o e r ch S.C., M c C l u r e K.E., W u 1 f D.M. (2005). Comparison of characteristics of lambs fed concentrate or grazed on ryegrass to traditional or heavy slaughter weights. I. Production, carcass, and organoleptic characteristics. J. Anim. Sci., 83: 679-685.

B o u g h a l m i A., A r a b a A. (2016). Effect of feeding management from grass to concentrate feed on growth, carcass characteristics, meat quality and fatty acid profile of Timahdite lamb breed. Small Rumin. Res., 144: 158-163.

Cañeque V., Velas co S., Díaz M.T., Pérez C., Huidobro F., Lauzurica S., Manz a n ares C., Gonzales J. (2001). Effect of weaning age and slaughter weight on carcass and meat quality of Talaverane breed lambs raised at pasture. Anim. Sci., 73: 85-95.

Cañeque V., Velasco S., Díaz M.T., de Huidobro F.R., Perez C., Lauzurica S. (2003). Use of whole barley with a protein supplement to fatten lambs under different management systems and its effect on meat and carcass quality. Anim. Res., 52: 271-285. 
C a r r a s c o S., P a n e a B., R i p o 11 G., S a n z A., J o y M. (2009 a). Influence of feeding systems on cortisol levels, fat colour and instrumental meat quality in light lambs. Meat Sci., 83: 50-56.

Carrasco S., Ripoll G., Sanz A., Álvarez-Rodríguez J., Panea B., Revilla B., J o y M. (2009 b). Effect of feeding system on growth and carcass characteristics of Churra Tensina light lambs. Livest. Sci., 121: 56-63.

CIE (1976). (Centre Internationale de L'Eclairage) Definition dun space de coleur por deux coordonees de cromaticite et la luminosite. Supplement 2 to CIE publication no 15 (E-1-3-1) 1971/ (TC-1-3). (Cente Internationale de L'Eclairage: Paris).

Díaz M.T., Vela s co S., Can eque V., Lauzurica S., Huidobro F., Perez C., Gonzales J., M a n z a n a res C. (2002). Use of concentrate or pasture for fattening lambs and its effect on carcass and meat quality. Small Rumin. Res., 43: 257-268.

Díaz M.T., Velasco S., Pérez C., Lauzurica S., de Huidobro R.F., Cañeque V. (2003). Physico-chemical characteristics of carcass and meat Manchego-breed suckling lambs slaughtered at different weights. Meat Sci., 65: 1085-1093.

E k i z B., A 1 t i n e 1 A. (2005). The possibilities of using German Blackheaded Mutton genotypes to get high quality lambs from Kivircik ewes. J. Fac. Vet. Med. Istanbul Univ., 31: 75-89.

Ekiz B., Yilmaz A., Ozcan M., Kaptan M., Hanoglu H., Erdogan I., Yalcintan H. (2009). Carcass measurements and meat quality characteristics of Turkish Merino, Ramlic, Kivircik, Chios and Imroz lambs raised under an intensive production system. Meat Sci., 82: 64-70.

Ekiz B., Yilmaz A., Ozcan M., K oc ak O. (2012 a). Effect of production systems on carcass measurements and meat quality of Kivircik lambs. Meat Sci., 90: 465-471.

Ekiz B., Ergül Ekiz E., Yalc intan H., K oc a k O., Yilmaz A. (2012 b). Effects of suckling length $(45,75$ and $120 \mathrm{~d})$ and rearing type on cortisol level, carcass and meat quality characteristics in Kivircik lambs. Meat Sci., 92: 53-61.

Ekiz B., Yilmaz A., Demirel G., Yalcintan H., Kocak O., Ozcan M., Altinel A. (2013). Slaughter characteristics, carcass quality and fatty acid composition of lambs under four different production systems. Small Rumin. Res., 114: 26-34.

En s e r M., Halle t K.G., Hew et t B., Fursey G.A.J., Wood J.D., Harrington G. (1998). Fatty acid content and composition of UK beef and lamb muscle in relation to production system and implications for human nutrition. Meat Sci., 49: 329-341.

F is her A.V., Ens er M., R i chardson R.I., Wood J.D., Nut e G.R., Kurt E. (2000). Fatty acid composition and eating quality of lamb types derived from four diverse breed $\times$ production systems. Meat Sci., 55: 141-147.

H e dri c k H.B., A b e r le E.D., F orrest J.C., Ju d ge M.D., Merkel R.A. (1994). Principles of meat science (3rd edn.). Kendall and Hunt Publishing Co., Iowa, USA.

Hoffman L.C., Muller M., Clo e te S.W.P., Schmidt D. (2003). Comparison of six crossbred lamb types: sensory, physical and nutritional meat quality characteristics. Meat Sci., 65: 1265-1274

H o p kin s D.L., H a 11 D.G., Chann on H.A., Hols t P.J. (2001). Meat quality of mixed sex lambs grazing pasture and supplemented with, roughage, oats or oats and sunflower meal. Meat Sci., 59: $277-283$.

I m mon en K., R u u s un en M., H is s a K., Pu o l a n n e E. (2000). Bovine muscle concentration in relation to finishing diet, slaughter and ultimate $\mathrm{pH}$. Meat Sci., 55: 25-31.

Juárez M., Horcada A., A lcalde M.J., Valera M., Mullen A.M., Molina A. (2008). Estimation of factors influencing fatty acid profiles in light lambs. Meat Sci., 79: 203-210.

Karabacak A., B oztepe S. (2007). Comparison of fattening performance of fat tailed and thin tailed sheep breeds. S. U. Ziraat Fak Derg., 21: 89-95.

Khliji S., van de Ven R., Lamb T.A., Lanza M., Hopkins D.L. (2010). Relationship between consumer ranking of lamb colour and objective measures of colour. Meat Sci., 85: 224-229.

L 1 o y d W.R., S ly te r A.L., C o s t e 11 o W.J. (1980). Effect of breed, sex and final weight on feedlot performance, carcass characteristics and meat palatability of lambs. J. Anim. Sci., 51: 316-320.

L o w e T.E., P e a c h e y B.M., D e v in e C.E. (2002). The effect of nutritional supplements on growth rate, stress responsiveness, muscle glycogen and meat tenderness in pastoral lambs. Meat Sci., 62: 391-397. 
Maiorano G., Ciarlariello A., Cianciullo D., Roychoudhury S., Manchisi A. (2009). Effect of suckling management on productive performance, carcass traits and meat quality of Comisana lambs. Meat Sci., 83: 577-583.

Martínez-Cerezo S., Sañudo C., Panea B., Medel I., Delfa R., Sierra I., Beltrln J.A., C e p e ro R., O 11 e t a J.L. (2005). Breed, slaughter weight and ageing time effects on physico-chemical characteristics of lamb meat. Meat Sci., 69: 325-333.

Özcan M., Ekiz B., Yilmaz A., Ceyhan A. (2005). Genetic parameter estimates for lamb growth traits and greasy fleece weight at first shearing in Turkish Merino sheep. Small Rumin. Res. 56: $215-222$.

Ö z c a n M., D e m i re 1 G., Ya k a n A., E k i z B., T ö l ü C., S a v a ş T. (2015). Genotype, production system, and sex effects on fatty acid composition of meat from goat kids. Anim. Sci. J., 86: 200-206.

Peña F., Bonvillani A., Freire B., Juárez M., Perea J., Gómez G. (2009). Effects of genotype and slaughter weight on the meat quality of Criollo Cordobes and Anglonubian kids produced under extensive feeding conditions. Meat Sci., 83: 417-422.

Perlo F., B on ato P., Te ir a G., T is o c co O., Vicentin J., Pue yo J., Mansilla A. (2008). Meat quality of lambs produced in the Mesopotamia region of Argentina finished on different diets. Meat Sci., 79: 576-581.

Petrova Y., Banskalieva V., Dimov V. (1994). Effect of feed on distribution of fatty acids at Sn-2-position in triacylglycerols of different adipose tissues in lambs. Small Rum. Res., 13: 263-267.

Priolo A., Micol D., Agabriel J. (2001). Effects of grass feeding systems on ruminant meat colour and flavour. A review. Animal Res., 50: 185-200.

Priolo A., Micol D., A gabriel J., Prache S., Drans field E. (2002). Effect of grass or concentrate feeding systems on lamb carcass and meat quality. Meat Sci., 62: 179-185.

R a j k u m a r V., D a s s G., Verm a A.K., D a s A.K. (2014). Slaughter weight effect on carcass and meat quality of Muzaffarnagari lambs in intensive production system. Indian J. Anim. Sci., 84: $569-574$.

R i c ardo H.A., Fernandes A.R.M., Mendes L.C.N., Oliveria M.A.G., Protes V., S c a t e n a E.M., Roça R.O., Athayde N.B., Girao L.V.C., Alves L.G.C. (2015). Carcass traits and meat quality differences between a traditional and an intensive production model of market lambs in Brazil: Preliminary investigation. Small Rumin. Res., 130: 141-145.

R ow e A., M a c e do F.A.F., Vis e n t a in er J.V., S o u za N.E., M a t s u s h it a M. (1999). Muscle composition and fatty acid profile in lambs fattened in drylot or pasture. Meat Sci., 51: 283-288.

Ş a h in Ö., B o zte pe S. (2010). Effect of initial live weights on fattening performance and carcass characteristics of Anatolian Merino male lambs I. Fattening performance. Selcuk J. Agr. Food Sci., 24: 25-29.

S a n to s V.A.C., S i lva S.R., M en a E.G., A zeve do J.M.T. (2007). Live weight and sex effects on carcass and meat quality of "Borrego terrincho-PDO" suckling lambs. Meat Sci., 77: 654-661.

S antos-Silva J., Mendes I.A., B e s s a R.J.B. (2002). The effect of genotype, feeding system and slaughter weight on the quality of light lambs. 1. Growth, carcass composition and meat quality. Livest. Prod. Sci., 76: 17-25.

Sañudo C., Alfonso M., Sánchez A., Delfa R., Teixeira A. (2000). Carcass and meat quality in light lambs from different fat classes in the EU carcass classification system. Meat Sci., 56: 89-94.

S a ñu d o C., S a n chez A., A 1 fo n s o M. (1998 a). Small ruminant production systems and factors affecting lamb meat quality. Meat Sci., 49: S29-S64.

S añudo C., Nute G.R., Campo M.M., Maria G., Baker A., Si erra I., Ens er M.E., Wo o d J.D. (1998 b). Assessment of commercial lamb meat quality by British and Spanish taste panels. Meat Sci., 48: 91-100.

Sezenler T., Soysal D., Y 11 d 1 r 1r M., Yüksel M.A., Ceyhan A., Yaman Y., Erdo$\breve{g}$ a n İ., Karada $\breve{g}$ O. (2013). Influence of some environmental factors on litter size and lamb growth performance in Karacabey Merino sheep. J. Tekirdag Agric. Fac., 10: 40-47.

Sylvestre M.N., Balcerzak D., Feidt C., Baracos V.E., Brun Bellut J. (2002). Elevated rate of collagen solubilisation and post-mortem degradation in muscles of lambs with high growth rates: Possible relationship with activity of matrix metalloproteinases. J. Anim. Sci., 80: 1871-1878. 
Teke B., Ekiz B., Akdag F., Ugurlu M., Ciftci G. (2018). Effect of lairage time after short distance transport on some biochemical stress parameters and meat quality of Karayaka lambs. Large Anim. Rev., 24: 41-44.

Vat a n s e ver L., D e m ir e 1 G. (2009). Fatty acid content and composition of Turkish beef and lamb at retail. Turk. J. Vet. Anim. Sci., 33: 71-75.

Velasco S., Lauzurica S., Caneque V., Perez C., Huidobro F., Manzanares C., Díaz M.T. (2000). Carcass and meat quality of Talaverana breed sucking lambs in relation to gender and slaughter weight. Anim. Sci., 70: 253-263.

Wi 11 i a m s C.M. (2000). Dietary fatty acids and human health. Annal. Zootech., 49: 165-180.

Wood J.D., Ens er M., F is her A.V., Nute G.R., Sheard P.R., R i chards on R.I., Hughes S.I., Whittingto n F.M. (2008). Fat deposition, fatty acid composition and meat quality: A review. Meat Sci., 78: 343-358.

Yalc intan H., Ekiz B., Kocak O., Dogan N., A kin P.D., Yilmaz A. (2017). Carcass and meat quality characteristics of lambs reared in different seasons. Arch. Anim. Breed., 60: 225-233.

Y i $1 \mathrm{maz}$ A., Ozcan M., Ekiz B., Ceyhan A., A 1 t in el A. (2004). The production characteristics of the indigenous Imroz and Kivircik sheep breeds in Turkey. AGRI-FAO, 34: 57-66.

Received: 29 VI 2018

Accepted: 5 II 2019 